\title{
PRELIMINARY STUDY FOR RETROFITTING OF A HISTORICAL WOODEN STRUCTURE USING BASE ISOLATION SYSTEM
}

\author{
C. CUADRA \& Y. FURUI \\ Akita Prefectural University, Japan.
}

\begin{abstract}
The old assembly hall of Noshiro city, Japan, that was built in 1950, was selected to analyse the possibility of its seismic retrofitting by means of installation of seismic isolation devices that reduce the lateral forces caused by earthquakes. The structure is a two-storey wooden frame with $20 \mathrm{~m} \times 29 \mathrm{~m}$ plan dimensions. The building consists of an office part at east side, gallery at west side and a main hall at the middle. It is planned to leave only the main hall and gallery as historic building and to demolish the office part. However, office part contributes also to lateral stiffness of the building and therefore evaluation of dynamic behaviour with and without office part is required. From ambient vibration measurements, periods of normal modes of vibration in main directions were estimated as 0.21 and $0.32 \mathrm{~s}$ for EW (large direction) and NS (short direction), respectively. Torsional mode of vibration was also detected at $0.16 \mathrm{~s}$. Then, finite element model was constructed and it was observed that analysis results are in good agreement with measurement results. Then dynamic properties of model without office portion were estimated as $0.23,0.25$ and $0.12 \mathrm{~s}$ for EW direction, NS direction and torsion, respectively. As retrofitting option, base isolation system is investigated considering $3 \mathrm{~s}$ as target period of the isolated structure. Due to the light weight of the upper structure, low-stiffness natural rubber isolators and sliding bearings were chosen as isolation devices. For that isolated building model, reasonable reduction of maximum acceleration on upper structure during earthquake was observed from analysis. Similarly, relative lateral displacement was reduced significantly. Therefore, retrofitting of historical wooden structures using base isolation devices represents a suitable alternative for improvement of their structural behaviour.
\end{abstract}

Keywords: base isolation, FEM, vibration analysis, wooden structure

\section{INTRODUCTION}

Most of the cultural heritage buildings in Japan are wooden structures that have been constructed using traditional methods [1]. These wooden structures are lighter than other historical structures like masonry buildings and reinforced concrete buildings. Then base isolation retrofitting for this kind of structures requires a detailed design of isolation devices since lateral stiffness of these devices affects significantly the dynamic characteristics of light structures.

Conventional methods for wooden construction are influenced by traditional ways of construction. However, at present, elements to increase lateral stiffness of constructions like braces, bolts and plates are used. Based on experience of damages due to earthquakes like Kobe of 1995 and Niigata Chuetsu of 2004, Japanese wooden standards have become stricter, and installation of such elements to increase stiffness is mandatory. For conventional new buildings, evaluation of earthquake-resistant characteristics can be done from well-known properties of reinforcing elements. On the other hand, intricate and complex joints in traditional wooden constructions make difficult their structural mechanic analysis, and moreover particular characteristics in each region contribute to make more difficult an unconditional evaluation of their earthquake-resistant characteristics [2], [3], [4]. Then it is necessary to evaluate case by case the dynamic properties for specific traditional wooden construction.

In this study, the Noshiro city assembly hall was selected as target structure to estimate its dynamic properties as a first step for its repair and conservation. Then a preliminary design 
for seismic retrofitting using base isolation system is performed. The building constructed in 1950 has been declared local cultural heritage building, and its structure corresponding to traditional wooden construction, however, differs from other traditional constructions like shrines or temple gates. The structure is a two-storey wooden frame with $20 \mathrm{~m} \times 29 \mathrm{~m}$ of plan dimensions. The building consists of an office part at east side, gallery at west side and a main hall at the middle. It is planned to left only the main hall as historic building and to demolish the office part. However, office part contributes also to lateral stiffness of the building and therefore evaluation of dynamic behaviour with and without office part is required. The base isolation system is planned for the building without office portion. The vibration characteristics of this reduced building are estimated from a model that was calibrated by comparing measurement results and analysis results using the complete building, and then office part is neglected analytically to obtain the target model. Dynamic properties of model without office portion were estimated as $0.23,0.25$ and $0.12 \mathrm{~s}$ for EW direction, NS direction and torsion, respectively. As retrofitting option, base isolation system is investigated considering $3 \mathrm{~s}$ as target period of the isolated structure. Due to light weight of the upper structure, low-stiffness natural rubber isolators and sliding bearings were chosen as isolation devices. Reasonable reduction of maximum acceleration response and significantly reduction of lateral relative displacement of upper structure during earthquake was observed from analysis.

\section{TARGET STRUCTURE: NOSHIRO CITY ASSEMBLY HALL}

The selected structure for this research corresponds to the Noshiro city assembly hall, located in Akita prefecture, in the north part of Japan. It was constructed in 1950 as a part of the city hall complex which was designed by the famous Japanese architect and structural engineer Kiyoshi Muto. At present, this city council building of Noshiro city has been declared as a building heritage at risk.

The structure corresponds to a two-storey frame wooden structure, however, to harmonize with the administrative building, which is a reinforced concrete construction, and the finishing was made of cement mortar. Figure 1 shows elevation views and the general plan view of the building. Dimensions of the building are approximately $20 \mathrm{~m}$ in front by $29 \mathrm{~m}$ in side direction. Figure 2a shows the main entrance of the target building situated at west side.

located at first floor.
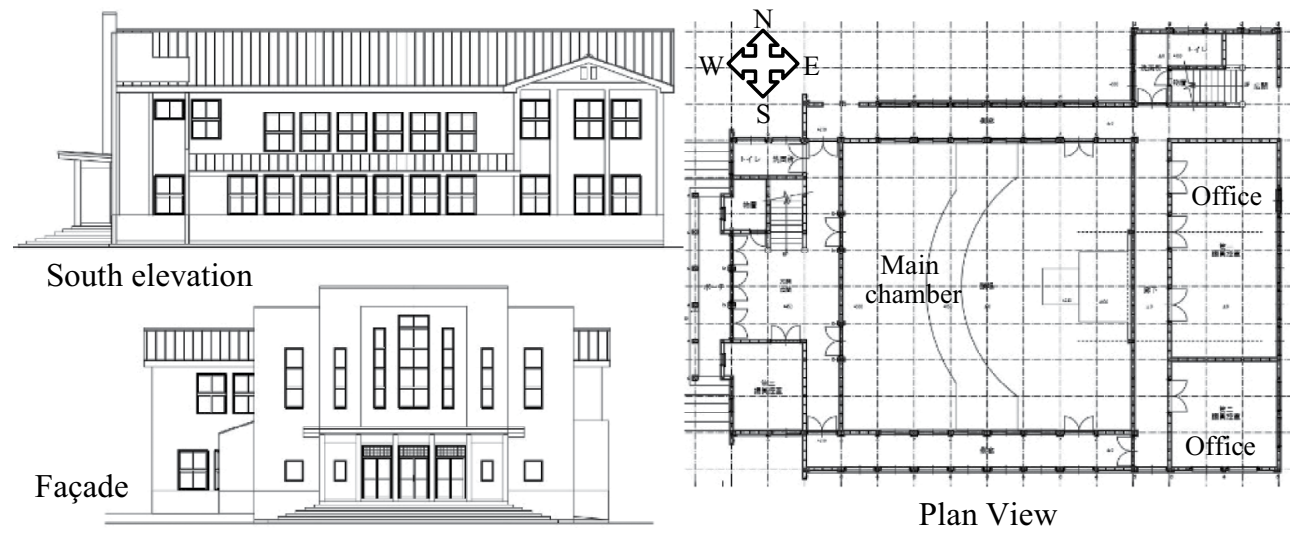

Figure 1: Elevation views and general plan view of Noshiro assembly hall. 


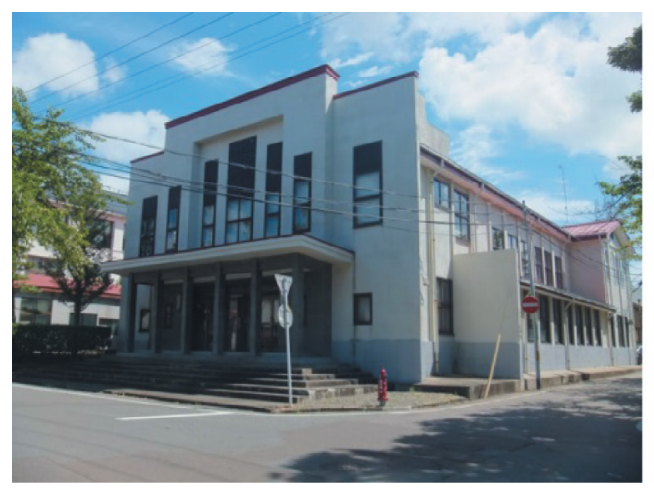

(a)

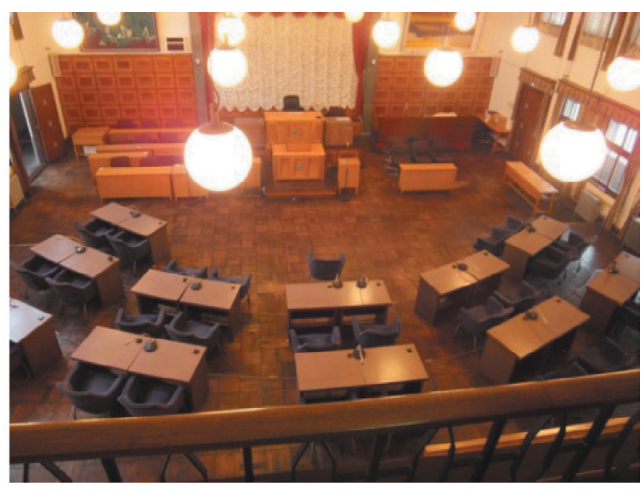

(b)

Figure 2: Façade and main chamber of Noshiro city assembly hall.

Large windows arranged in the entrance porch and side parts with a western-style design can be observed. Figure $2 \mathrm{~b}$ also shows a view of the interior of the assembly hall located at first floor.

At west side in the second floor, near the building entrance, are located galleries or stands for the public. Photograph of Fig. $2 b$ was taken from the stands for the public. In this part are also located offices for chairman and secretary. Offices of assembly members and administrative offices are located at east part in the first and second floors (right part in Fig. 2a). Details of a wall behind chairman desk can be observed in Fig. 3a, where cement mortar was used for finishing. This finishing mortar also contributes to lateral stiffness of building. Curtains and wooden finishing are only decorative elements. Figure $3 \mathrm{~b}$ shows a photograph of galleries taken from the main chamber. This figure also shows the ceiling of the main chamber which was originally made of cement mortar. However, due to ageing deterioration a sudden falling of some portion of ceiling occurred in December 1998, and ceiling was reconstructed using plaster board that is fixed to a wooden structure with screws. Roof is supported by a truss structure forming a gable roof.

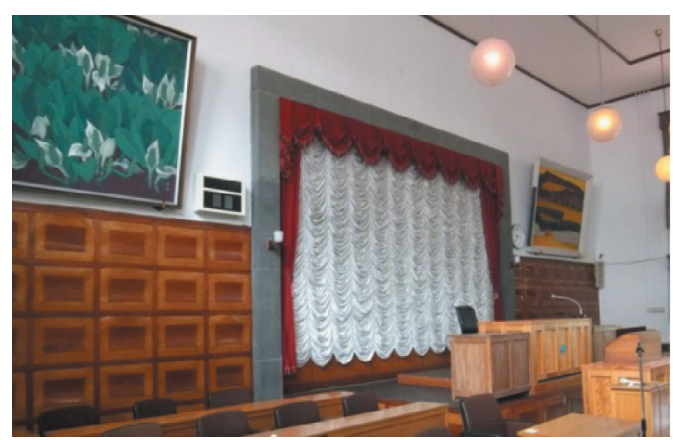

(a)

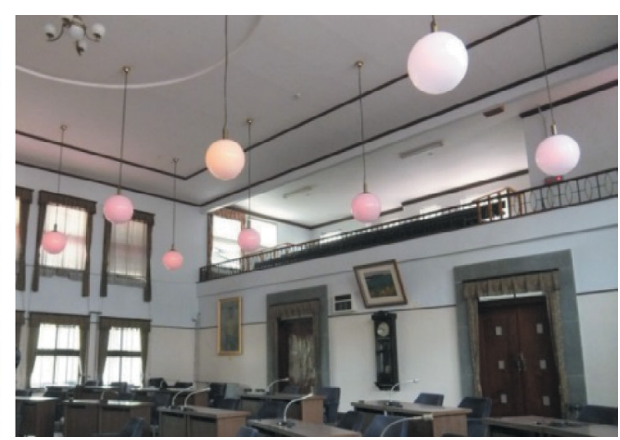

(b)

Figure 3: Detail of interior wall and detail of gallery and ceiling. 


\section{AMBIENT VIBRATION MEASUREMENTS}

Micro-vibrations of target building were measured conforming to the diagrams that are shown in Fig. 4. Since it is assumed that wooden structures are flexible, dynamic characteristics of this type of building can be estimated from Fourier spectrum analysis of signals recorded at upper floors [5], [6], [7]. A set of measurements were done conforming to the scheme of Fig. 4, where simultaneous measurements were carried out to identify also the torsional mode of vibration.

Results of measurement on target building are presented for the short direction that is parallel to the façade and for the longitudinal direction. To estimate the dynamic characteristics of target building a stable portion of the record, with $40.96 \mathrm{~s}$ of duration, is taken to perform a Fourier analysis. Only Fourier spectrum is used to estimate the predominant period of the building. Moreover, to estimate the torsional mode of vibration, Fourier spectrum of the relative velocity between two points of measurements is used. As example, the result of the Fourier analysis is shown in Figs. 5 and 6. Figure 5 shows the results for each horizontal direction, and predominant frequencies are estimated as $3.00 \mathrm{~Hz}$ for short direction and 4.86 for longitudinal direction.

Table 1 shows the summarized results from a set of measurements. Average values of 4.86 and $3.09 \mathrm{~Hz}$ are obtained for longitudinal and short directions, respectively.

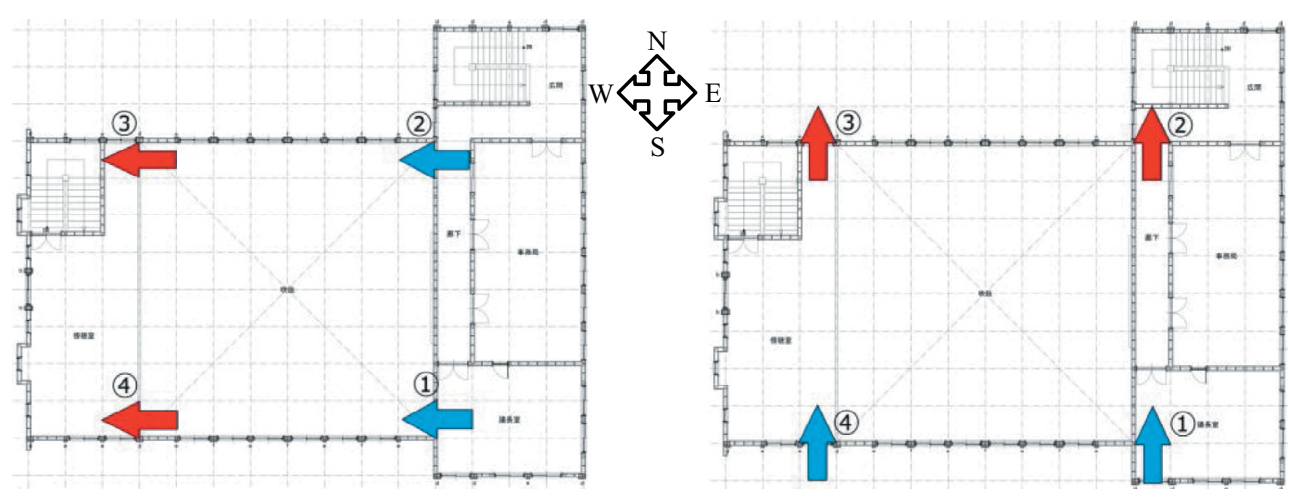

Figure 4: Scheme for simultaneous measurements.

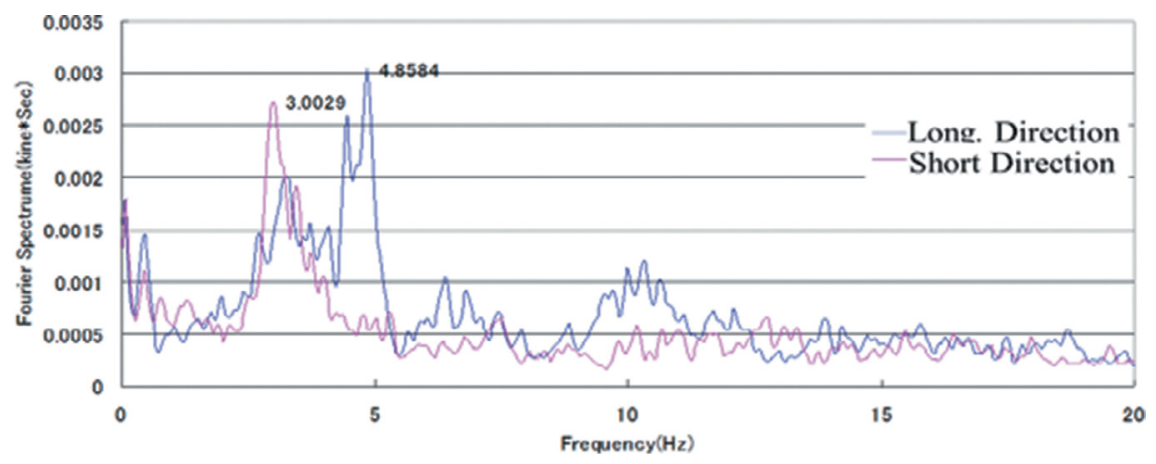

Figure 5: Fourier spectrum results. 
Table 1: Results for the second set of measurements.

\begin{tabular}{ccc}
\hline \multirow{2}{*}{ Point of measurement } & \multicolumn{2}{c}{ Predominant frequency (Hz) } \\
\cline { 2 - 3 } & Large direction & Short direction \\
\hline (1) & 4.88 & 3.32 \\
(2) & 4.83 & 3.02 \\
(3) & 4.86 & 3.00 \\
(4) & 4.86 & 3.01 \\
\hline
\end{tabular}

Table 2: Predominant frequencies for torsional mode of vibration.

\begin{tabular}{cc}
\hline Points for relative velocity & Predominant frequency $(\mathrm{Hz})$ \\
\hline (1)-(2) & 6.30 \\
(3)-(4) & 6.25 \\
(1)-(4) & 6.49 \\
(2)-(3) & 6.59 \\
\hline
\end{tabular}

Since measurements were performed simultaneously at all points, it was possible to obtain the torsional mode of vibration. For this purpose, Fourier spectrum of the relative velocity of two points (e.g. the difference between points 1 and 4 in longitudinal direction) was calculated to identify the torsional mode of vibration. The result is presented in Fig. 6, and a clear peak is observed at $6.49 \mathrm{~Hz}$.

Results for torsional mode of vibration are summarized in Table 2. These predominant frequencies were estimated from Fourier spectrum of relative velocity between indicated points. Average value for the frequency of torsional mode is $6.41 \mathrm{~Hz}$.

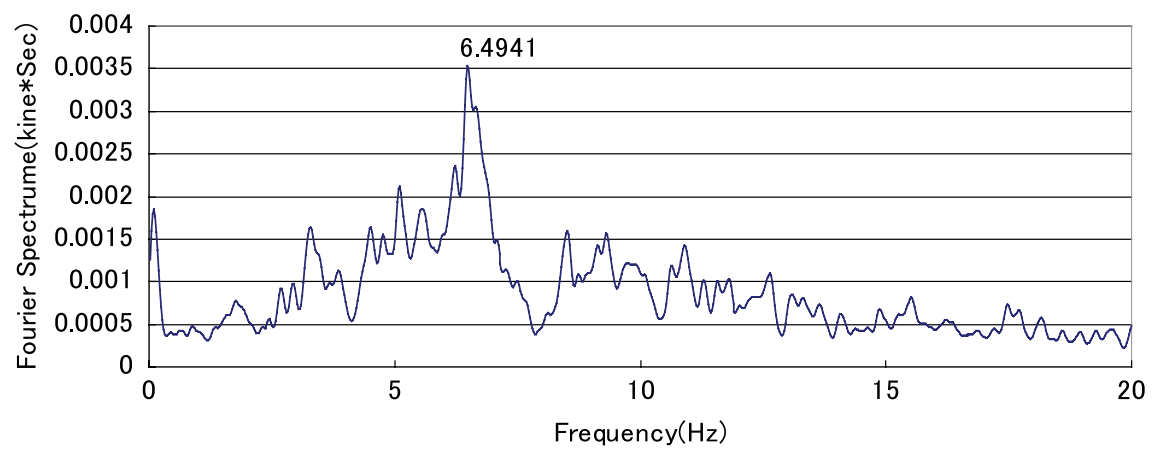

Figure 6: Fourier spectrum of relative velocity. 


\section{FINITE ELEMENT MODEL AND RETROFIT ANALYSIS}

To calibrate the model for analysis the original structure was modelled using finite element method (FEM). Then dynamic characteristics obtained from ambient vibration measurements are compared with those obtained from analysis. Then the office portion of the building is neglected, and dynamic properties of this modified structure are obtained analytically. Figure 7 shows structural models of both structures. The FEM model was constructed based on available data and based on direct measurements of the dimension of the building. As observed in Fig. 7, the general shape of Noshiro city assembly hall is reproduced in the model using frame elements for walls and truss elements for roof structure. Wood elements are made of Akita cedar with elastic modulus of 7,500, 600 and $300 \mathrm{~N} / \mathrm{mm}^{2}$, for longitudinal, radial and tangential axes, respectively.

Finite element model of the original structure consists of 2,327 frame elements for main structure including roof truss and 400 area elements for slabs and roof. Roof is made of metal plate and is modelled as shell structure supported by a truss system. Ceiling and floor slabs are wooden structures and additional mass is considered for plaster finishing. To construct the FEM model, characteristics of the joints were estimated considering that joints present partial stiffness. The office part of the model was deleted to obtain the modified structure. Then, from modal analysis, vibration characteristics of both models are obtained. Table 3 shows these results, and it can be observed that normal modes of vibration for modified structure have lower frequencies for both directions. This is due to the fact that although the structure has smaller mass, the lateral stiffness has also suffered a reduction resulting in lower predominant frequencies. In the case of torsional mode of vibration, the frequency presents a
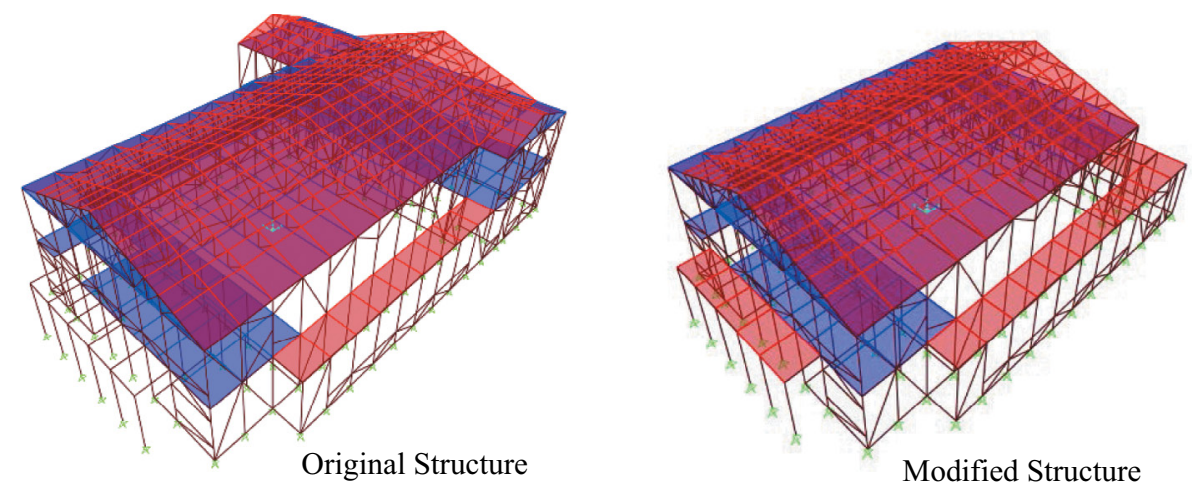

Figure 7: Original structure and modified structure.

Table 3: Vibration characteristics of original and modified structures.

\begin{tabular}{llcc}
\hline Structure & Mode of vibration & Period (s) & Frequency $(\mathrm{Hz})$ \\
\hline Original structure & Longitudinal direction & 0.25 & 4.00 \\
& Short direction & 0.21 & 4.68 \\
& Torsion & 0.18 & 5.62 \\
Modified structure & Longitudinal direction & 0.25 & 3.93 \\
& Short direction & 0.23 & 4.41 \\
& Torsion & 0.12 & 8.39 \\
\hline
\end{tabular}


higher value for the modified structure. It means that this mode of vibration will not occur at low frequencies since the structure is more symmetric than the original one.

For the modified structure, seismic retrofitting using base isolation system is investigated. Since the upper structure is a light wooden structure, natural rubber isolator of low lateral stiffness is selected to provide the required stiffness of isolated layer. These rubber isolators are combined with sliding isolators to increase the energy dissipation capacity of the system. A concrete slab and corresponding foundation beams are considered to install the isolation layer. This slab result in a weight of $3,800 \mathrm{kN}$, while the weight of upper structure has a weight of $500 \mathrm{kN}$.

Considering $3 \mathrm{~s}$ as the target period of isolated building to be designed, the required lateral stiffness of isolated layer is $18.4 \mathrm{kN} / \mathrm{cm}$. A quantity of 42 rigid sliding bearings GSD90 with a friction coefficient of 0.0046 are considered. Also, ten restoring force rubber isolators are considered to contribute to lateral stiffness of the system. The clearance is estimated as $50 \mathrm{~cm}$. The slab modelling and distribution of isolation devices are shown in Fig. 8.

As input motions, near-source earthquake records (three waves) and far-source earthquake records (two waves) are employed. The objective is to consider short period-type earthquakes and long period-type earthquakes. To facilitate the comparison of analysis results, all signals are normalized to have $50 \mathrm{~cm} / \mathrm{s}$ as maximum velocity. Characteristics of the earthquake records are shown in Table 4 . Time history analysis is performed considering $2 \%$ as viscous

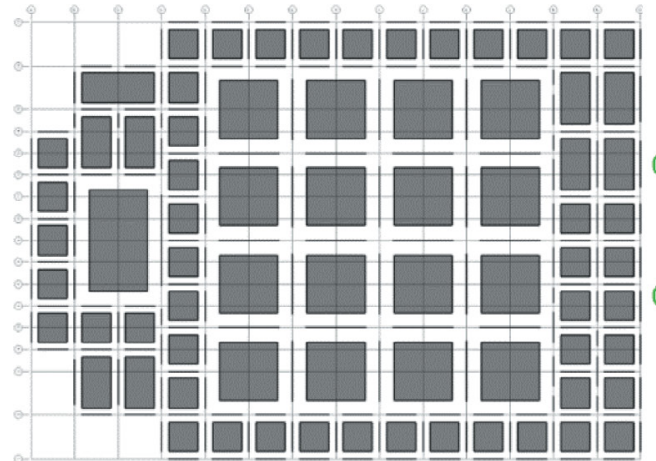

Slab modelling partition

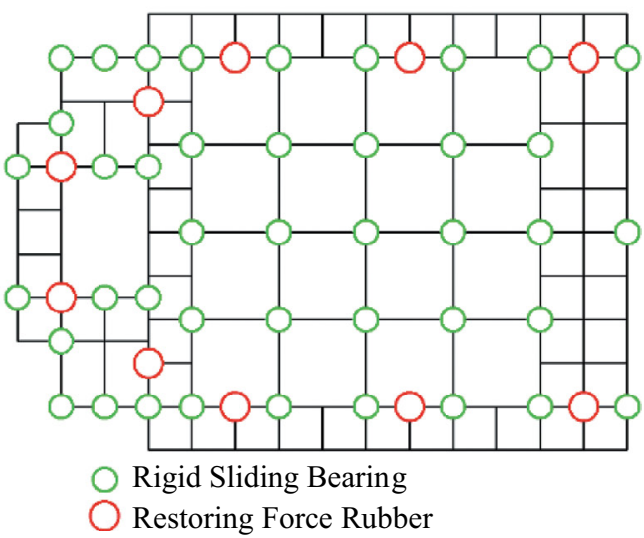

Figure 8: Slab modelling and distribution of isolation devices.

Table 4: Characteristics of input motions.

\begin{tabular}{llccc}
\hline Record name & Earthquake details & $\begin{array}{l}\text { Maximum } \\
\text { acceleration } \\
\left(\mathrm{cm} / \mathrm{s}^{2}\right)\end{array}$ & $\begin{array}{l}\text { Maximum } \\
\text { velocity } \\
(\mathrm{cm} / \mathrm{s})\end{array}$ & Duration (s) \\
\hline ELC-NS & Imperial Valley, 1940 (ElCentro) & 510.8 & 50 & 53.76 \\
Taft-EW & Kern County, 1952 (Taft) & 496.6 & 50 & 54.38 \\
Kobj-NS & Hyogo Prefecture, 1995 (Kobe) & 423.9 & 50 & 50.0 \\
Hach-NS & Tokachi-oki, 1968 (Hachinoje NS) & 333.5 & 50 & 234.0 \\
Hach-EW & Tokachi-oki, 1968 (Hachinoje EW) & 239.8 & 50 & 234.0 \\
\hline
\end{tabular}


damping of the system while equivalent damping is proportioned by the sliding bearings. Each unidirectional input motion was input separately for $X$ direction (large side direction of building) and $Y$ direction (short side direction of building).

Results of analysis are shown in Figs. 9 and 10. Maximum accelerations for ground (input), floor slab (isolated floor), mezzanine (gallery) and roof (top) are shown in Fig. 9. Reduction of input acceleration is observed for both directions, and reduction factors vary from 0.1
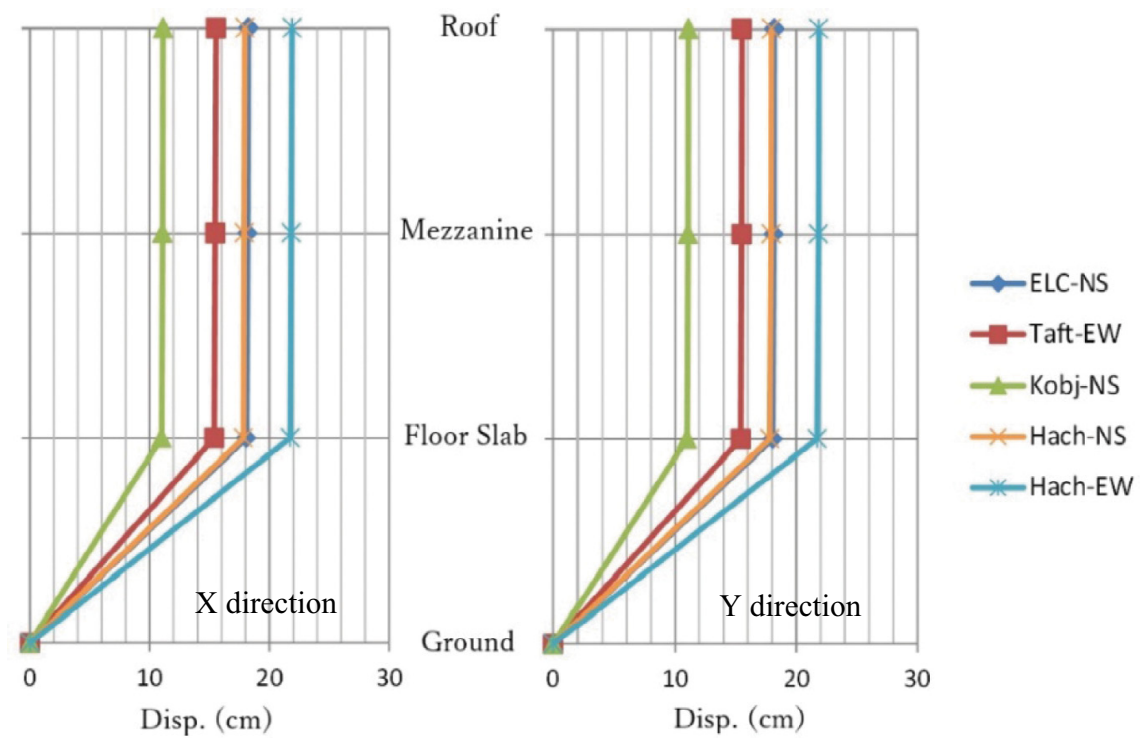

Figure 9: Maximum acceleration responses.

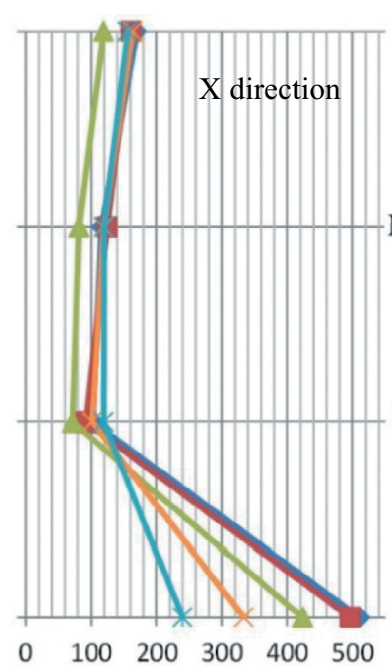

Acc. $\left(\mathrm{cm} / \mathrm{s}^{2}\right)$

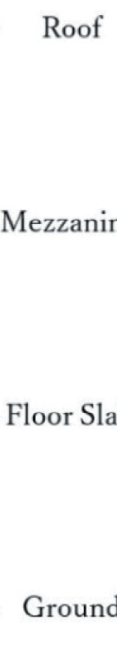

Figure 10: Maximum displacement responses. 
to 0.5. Results for displacement are shown in Fig. 10 and it can be observed that displacements are concentrated at floor slab. However, all maximum displacements are smaller than the clearance of $50 \mathrm{~cm}$ (maximum displacement of $22.9 \mathrm{~cm}$ ). On the other hand, relative displacements of upper part are very small.

\section{CONCLUSIONS}

An analysis for a seismic retrofit of a historical wooden structure using base isolation devices has been performed. The applicability of this kind of retrofitting has been analytically proved.

Effectiveness in reduction of maximum acceleration was demonstrated for all input motions used in the analysis. Reduction factors varying from 0.1 to 0.5 were obtained.

A maximum displacement of 22.9 for the isolated structure is small enough to avoid the impact against retaining walls since a clearance of $50 \mathrm{~cm}$ is considered in the design.

\section{REFERENCES}

[1] Uchida, S., Maegawa, S. \& Kawai, N., Vibration characteristics of traditional wooden heritages structures. Summaries of Technical Papers of Annual Meeting, Architectural Institute of Japan, Part 1 to Part 10, Kanto, Tokyo, 2001 (in Japanese).

[2] Ueta, K., Cuadra, C., Tokeshi, K. \& Karkee, M. B., Seismic behavior of thatch house at Minehama village in Akita, Japan. Tenth International Conference on Structural Studies, Repairs and Maintenance of Heritage Architecture, STREMAH X, Prague, Jul. 2007, pp. 667-673.

[3] Igarashi, N., Cuadra, C. H., \& Oshikiri, S., Dynamic properties of traditional wooden temples located in Yurihonjo city, Japan. 14th European Conference on Earthquake Engineering (14ECEE), Ohrid, Macedonia August 30-September 3, 2010. Paper Number: 392.

[4] Cuadra, Carlos H., Shimoi, Nobuhiro, Nishida, Tetsuya \& Saijo, Masahiro, Estimation of dynamic properties of traditional wooden structures using new Bolt Sensor. 13th International Conference on Control, Automation and Systems (ICCAS 2013), 20-23 October, 2013, Kimdaejung Convention Center, Gwangju, Korea

[5] Cuadra, C., Yamada, Y. \& Narumi, R., Evaluation of dynamic properties of traditional wooden shrines in Yurihonjo, Japan. WIT Transactions on the Built Environment, 131, pp. 471-480, (C) 2013 WIT Press doi:10.2495/STR130391

[6] Cuadra, Carlos H., Nishida Tetsuya \& Shimoi, Nobuhiro, New piezoelectric Bolt Sensor for estimation of dynamic properties of wooden structures. The 2014 International Conference on Systematic Innovation, San Jose, the USA, Paper No.49 (2014)

[7] Cuadra, C., Saito, T., \& Zavala, C., Diagnosis for seismic vulnerability evaluation of historical buildings in Lima, Peru. Journal of Disaster Research, 8(2), pp. 320-327, Mar. 2013, Special Issue on Enhancement of Earthquake and Tsunami Disaster Mitigation Technology in Peru. DOI: 10.20965/jdr.2013.p0320. 